Article

\title{
Understanding the Living Conditions of Chinese Urban Neighborhoods through Social Infrastructure Configurations: The Case Study of Tianjin
}

\author{
Xuan Sun ${ }^{1,2}$, Weikai Wang ${ }^{3}$, Tao Sun ${ }^{1, *}$ and Ya Ping Wang ${ }^{3}$ \\ 1 Zhou Enlai School of Government, Nankai University, Tianjin 300350, China; sunxuan@nankai.edu.cn \\ 2 Experimental Teaching Center of Applied Social Science, Nankai University, Tianjin 300350, China \\ 3 School of Social \& Political Sciences, University of Glasgow, Glasgow G12 8RS, UK; \\ w.wang.3@research.gla.ac.uk (W.W.); yaping.wang@glasgow.ac.uk (Y.P.W.) \\ * Correspondence: suntao@nankai.edu.cn; Tel.: +86-139-2030-8939
}

Received: 19 August 2018; Accepted: 6 September 2018; Published: 11 September 2018

\begin{abstract}
Under the unprecedented wave of urbanization and pace of economic development, the living conditions of residents have been unevenly changed in Chinese cities. To understand the diversified living conditions in Chinese urban neighborhoods from the supply-side point of view, new spatial and residential data were gathered to investigate the social infrastructure configurations around the residential communities. Using Tianjin as a case study, the research focuses on six important categories of human needs: education, healthcare, leisure, culture, entertainment, and transportation. Based on the cumulative accessibility measurements of 25 types of facilities, the social infrastructure configurations within neighborhoods are statistically and spatially analyzed and compared. The study discovered that: (1) despite the great diversity of living conditions in the city, the neighborhoods that have better services and strong associations with entertainment and education are prominent; (2) the neighborhoods with advantageous living conditions in different aspects tend to cluster at different places; (3) the neighborhoods of different types of communities, belonging to different administrative districts, or in different urban zones, all have distinctive characteristics in living conditions.
\end{abstract}

Keywords: social infrastructure; living condition; neighborhood; urban environment; China

\section{Introduction}

People's daily lives in cities are always hot topics among social researchers [1]. As a reflection of the comprehensive opportunities to satisfy physical and mental demands, the quality of life determines the well-being of residents in many aspects [2]. In the last two decades, a great number of countries in Asia and Africa have experienced an unprecedented wave of urbanization, and hundreds of millions of people have moved from the countryside to cities [3]. Although the general economic and built environments improved substantially along with this process of urban growth, the living conditions of urban residents were unevenly affected [4,5]. Limited resources and large-scale migration often resulted in congregated distributions of social infrastructures, and offered unequal opportunities for different social and economic groups to enjoy services that bring about various patterns of life in cities.

China is one of the countries with fastest urbanization progress from the 1990s to now [6]. Under the dramatic paces of economic development and spatial changes, not only large disparities in the provision of public services can be observed among different regions and between urban and rural areas, but also the diverse groups and multifaceted experiences of living are widely found within cities [7]. Driven by the force of industrialization and urban development and renewal, the social life and welfare system has been improved significantly, but poverty and inequality still exist in lots 
of places $[8,9]$. While the life quality is greatly enhanced among the emerging middle-class people living in new or gentrified areas [10], most urban low-income residents and rural migrants found in the dilapidated inner-city neighborhoods, urban villages, or peri-urban areas by contrast do not live a pleasant life [11,12].

To understand life in urban China, new technologies and data sources have been employed recently to study the activities of residents and the influences from the environments. With the mobile telephone-based sensor data, the spatial and temporal differences in everyday activities were explored [13]. Using the social media check-in data, the human mobility within the city was studied [14]. Through the data mining of the records generated by the subway system, the patterns of group travel behaviors were analyzed [15]. The relationship between elderly people's health and living in residential care facilities was discussed based on qualitative data collected from semi-structured interviews [16]. According to activity-travel diary data from a sample of households before and after they moved from one residential location to another, the associations between the built environment and travel behavior were explained [17]. Comparing with the direct investigations on the individuals' behaviors, residents' accessibility to public services is a relatively new and understudied topic that could give some intuitional views of the people's living conditions from the supply side [18,19]. As human's activities are highly limited by various space-time constraints [20], distance does have a great impact on the social benefits of public facilities [21]. The infrastructure development level in the neighborhood is the most important factor for residents' daily life [22].

This paper takes Tianjin as an example to explore the diverse living conditions of Chinese urban neighborhoods by means of the quantitative studies of the social infrastructure configurations. The remaining parts of the paper are organized as follows. In Section 2, the basic life demands and social infrastructure developments in Chinese cities are introduced. Section 3 elaborates the rationale of living condition analysis at the neighborhood level. Section 4 describes and discusses the living conditions of the neighborhoods in Tianjin from different perspectives. Finally, the paper is briefly concluded with the statements of findings, practical implications, and limitations of our research in Section 5.

\section{Living Demands and Social Infrastructure Developments in Urban China}

Education opportunities, health care, culture experience, leisure and entertainment activities, and commuting capabilities are generally considered as the major demands of contemporary urban lives. Unlike the infrastructures for economic developments, social infrastructures are the facilities and venues that mainly serve the various needs of residents in daily life $[23,24]$. Accompanied with the process of rapid urbanization, China has also developed, and been gradually improving its social infrastructure system to satisfy the demands of residents in different aspects [25].

\subsection{Education}

As the basis of both individual and social development, education plays a significant role in urban lives. From kindergarten, primary school, and middle school to high school, a good education environment is always the pursuit of residents [26]. Living in a neighborhood adjacent to education facilities can effectively reduce the time spent on the traveling to school, and it also means an advantageous living condition. In the favorable atmosphere of learning, the residents are more likely to live with cultivated neighbors and enjoy a lower crime rate in their communities [27].

In China, education is always highly valued. The government has issued a number of laws and policies to protect the basic rights of the people for receiving education throughout the whole process of growing up [28]. However, the uneven distribution of education resources makes it a capital competition in the society to be settled near schools. Owning to the spatial mismatch of residence and education facilities, home-school and home-kindergarten travel has become an important part of many people's daily life [29]. Especially under the nearby enrollment policy on primary and secondary 
schooling, a housing district with high-quality schools is desirable for almost all of the families with children [30].

\subsection{Healthcare}

Healthcare is another focus of concern in urban lives. As the main source of medical treatment and public health services, the hospitals and clinics at different levels take on most of the city functions to address the diversified healthcare needs of residents. Not only the quantity and quality, but also the accessibility of the facilities are the key factors that decide the healthcare condition of a city [31]. The convenient access to high-quality medical services usually means a healthier living environment [32], and to satisfy the increasing demands of a high quality of life, more attention is being given to community healthcare [33].

Due to the large population, it is hard to ensure high-quality healthcare services for everyone in China. Although the majority of healthcare facilities are public-owned and the healthcare system is government-led, the inequality of medical services is still a big problem [34]. The unified prices of treatments in public hospitals and the freedom of choices from patients make the spatial distribution of healthcare facilities the most influencing factor of the service capability. Through the uniformly distributed community health centers, equal primary healthcare services are actually provided [35]. However, as there is no mature hierarchical diagnosis system in China, under the pursuit for better treatments, most patients prefer to go to big general hospitals, even for minor illness [36].

\subsection{Leisure}

Leisure activities are of great importance to the people's everyday life. Frequent contact with nature and regular exercise can help us keep healthy bodies and maintain good moods. After intense work and study, the residents often tend to do some strolling or light sports for rest and relaxation purposes [37]. The parks, activity centers, and gyms play a major role in providing outdoor and indoor places for leisure in cities, and the access to these leisure facilities is increasingly related to the people's quality of life and well-being [38].

With the improvements of living standards, the lifestyles of the people changed greatly in China. Nowadays, more and more residents want to live a healthy life with plenty of opportunities for physical exercise and relaxation [39]. For the promotion of the grassroots leisure activities in daily life, the government has done a lot of work in facility development and service delivery [40]. However, no matter how many urban parks or sport facilities exist, spatial distance is still one of the major factors that restricts the utilization in many cases [41,42]. Among all of the leisure facilities, only those that are reachable within a limited commuting time from dwellings are frequently visited by the local inhabitants.

\subsection{Culture}

Culture is also a determinant factor of the subjective well-being (SWB) of the people. Aside from the environment effects, the cultural infrastructures, such as libraries, museums, and religious sites do have a significant impact on the social life of residents [43]. They are not only the places for education and learning, art edification, and religious events, they also provide opportunities to meet and interact with others, enhance relationships in families, and promote social cohesion in the community [44]. In urban districts, the culture clusters are always associated with a variety of positive features of neighborhoods [45].

Driven by the forces of urban regeneration and suburbanization, the cultural infrastructures have undergone great development in most Chinese cities during the past decades [46]. Although the infrastructures are usually designed and constructed to serve at the municipal level, the external benefits are obvious in the nearby housing areas. They not only helped to shape places in cities [47], they also facilitated the cultural activity participation of the residents who live in the surrounding communities [48]. Meanwhile, due to the historical preservation and the immigration of upper-class 
residents, the surrounding residential communities are likely to be gentrified through the processes of physical space renovation and shifts in culture and lifestyle [49].

\subsection{Entertainment}

The pursuing of happiness is one of the non-negligible elements of daily lives. With the arrival of the post-industrial age, entertainment has been gaining more and more popularity among citizens [50]. To meet the increasing needs of recreation and amusement, theaters, cinemas, and various pubs and shopping malls sprang up in cities around the world. Nevertheless, the social benefits are in effect not equally enjoyed by all of the residents [51]. The hot zones of entertainment are determined by the spatial distribution of the corresponding facilities [52].

Benefiting from the marketization and economic development, the entertainment industry has also been greatly developed in China [53]. Compared to entertainment in the past, more choices are offered in the market for entertainment consumption nowadays. With the aim of enriching the spiritual life of individuals, among all of the facilities, cinema and theaters are especially welcomed in the new millennium [54]. At the same time, the modern shopping malls that integrate multiple entertainment events indoors are becoming one of the most frequently visited places of residents in their spare time [55]. Between the demands and service provision, the utilization rates of the facilities are largely influenced by their accessibility [56].

\subsection{Transportation}

Transportation means a lot to the daily life of residents. It not only plays an important role in the commute to work, it also supports the various activity-travel behaviors in the city [57]. The stronger the transportation capability is at a place, the more meaningful interactions, pleasures, and cultural productions tend to arise there [58]. In view of the efficiency and the environmental effect, public transportation is of crucial importance to big cities. While the station locations have a great impact on the usage of the transport system [59], the travel conditions would to some extent decide the cognitive SWB of the people [60].

Despite the increasing private car ownership, public transportation is the main mode of travel in urban China. The bus, tram, trolley, and subway together make up the core transport system, and the daily travel behaviors vary greatly with the dwelling places of the residents in a city [61]. In general, the number of traffic options within the walking distance and the convenience of traveling trips are the two key factors determining the people' satisfaction with the public transportation [62]. To promote local economic activities and increase the quantity and diversity of consumer amenities, the subway systems have undergone enormous development since the late 2000s [63]. However, the uncoordinated developments of the transportation system and urbanization have also brought about traffic congestion to cities [64].

\section{Living Condition Analysis at the Neighborhood Level}

The living space of residents can be divided geographically into different circles according to the frequencies of activities [65]. Among all of the activity regions, the 15-minute community life circle is the one that satisfies most of the demands in daily lives [66]. Thus, the living condition of the neighborhood with the limited walking distance from the dwelling is the major determinant for the lifestyle of the ones living there [67].

\subsection{Social Infrastructure Configuration within the Neighborhood}

Aside from the requirements of safety and comfort at the material level, the function structure of the neighborhood is significantly related with the satisfaction of residents in the living conditions. Within the endurable walking distance scope, allocating as many beneficial services as possible is the key to ensure the high quality of daily life. 
Infrastructures are the carriers of various public services. Different configurations of infrastructures would result in different chances to enjoy the services in the specific areas [68]. Although there are strong regulations on the construction of infrastructures in the urban planning documents, due to the development demands and historical reasons, the social infrastructures are always unevenly distributed among neighborhoods in the city. With consideration of the service utilities, the living condition of each neighborhood can be regarded as the combination of the opportunities for social infrastructure visits in the daily life, and be expressed with the following formula:

$$
C_{n}=\cup_{i} O_{n, i}
$$

where $C_{n}$ is a parameter set representing the living condition of the neighborhood $n$, and $O_{n, i}$ stands for the opportunities to visit the type $i$ social infrastructure within the neighborhood $n$.

\subsection{Accessibility Measurement for Living Condition Analysis}

Accessibility is one of the commonly used terms and measurements to reveal the degree of availability of things under certain constraints. Determined by the cost of time, distance, and energy, it can well reflect the opportunities of service acquirement in the physical world $[69,70]$. For quantitative analysis of the living conditions of neighborhoods, the accessibilities to different types of social infrastructures are calculated as the core indicators.

The measurement of accessibility can be calculated with a number of methods [71]. In the field of transportation, the distance and travel time are always accurately measured to determine the accessibility from the points of concern to the destinations in geography [72]. Besides, with full consideration of both travel demands and the capability of service providers, accessibility is measured from the perspective of the uniform utilization of resources [73]. Compared with the geography-based model and the utility-based model, a cumulative accessibility index is adopted here to describe the visiting opportunity of a certain type of social infrastructure within a limited spatial scope. Taking into account the availability of all of the related facilities, the index can be calculated with the following formula:

$$
\operatorname{Ind} x\left(O_{n, i}\right)=\sum_{j} w_{i, j} a\left(t_{n, i, j}\right),
$$

where $\operatorname{Indx}\left(O_{n, i}\right)$ stands for the cumulative accessibility index that reflects the visiting opportunities of the type $i$ social infrastructure within the neighborhood $n, w_{i, j}$ is the importance coefficient (e.g., the capability, quality, or some priority) of the specific facility $j$ among all of the ones of type $i, t_{n, i, j}$ is the "impedance" (e.g., the cost of time, distance, or energy) to visit facility $j$ of type $i$ within the neighborhood $n$, and $a\left(t_{n, i, j}\right)$ is the availability function.

\section{Case Study of Tianjin}

Tianjin, the economic center of northern China, is one of the typical cities that have experienced fast economic and social developments in recent decades. It played an important role in the modern history of China, and now more than 15 million people live there. In the last 10 years, the gross domestic product (GDP) has tripled, and the housing space has increased fivefold. As an epitome of Chinese urbanization progress, the changes of living conditions in Tianjin are representative. With consideration of the concentrated inhabitants and living facilities there, the central districts of the city are chosen as the study area of our research.

The research data is mainly twofold: the points of interest (POI) map and the housing database of Tianjin in 2017. The POI map, which is bought from a credible navigation company [74], provides the exact location of every infrastructure facility and residential community in the geographic information system (GIS). The housing database, crawled from a popular house selling website [75], includes the physical characteristics of each community, such as the plot ratio, greening rate, and management fee. 
For discussions of the living conditions of various neighborhoods, this paper focuses on 25 types of social infrastructures, which are divided into six categories in accordance with the major demands of residents in their daily lives (see Section 2 for details):

- Education facilities: public kindergarten, private kindergarten, key primary school, primary school, key middle school, middle school, high school, technical school (see Figure 1a);

- Health facilities: large general hospital, general hospital, specialized hospital, community clinic (see Figure 1b);

- Leisure facilities: grand park, small park, activity center, gym (see Figure 1c);

- Cultural facilities: library, museum, attraction place, religious site (see Figure 1d);

- Entertainment facilities: cinema, theatre, shopping mall (see Figure 1e);

- Commuting facilities: bus stop, subway station (see Figure 1f).

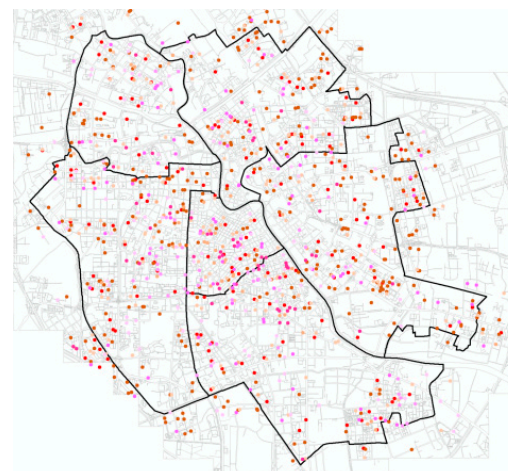

- Public kindergarten Key primary school Normal primary schoo
Key middle school Normal middle schoo High school

(a) Education infrastructures
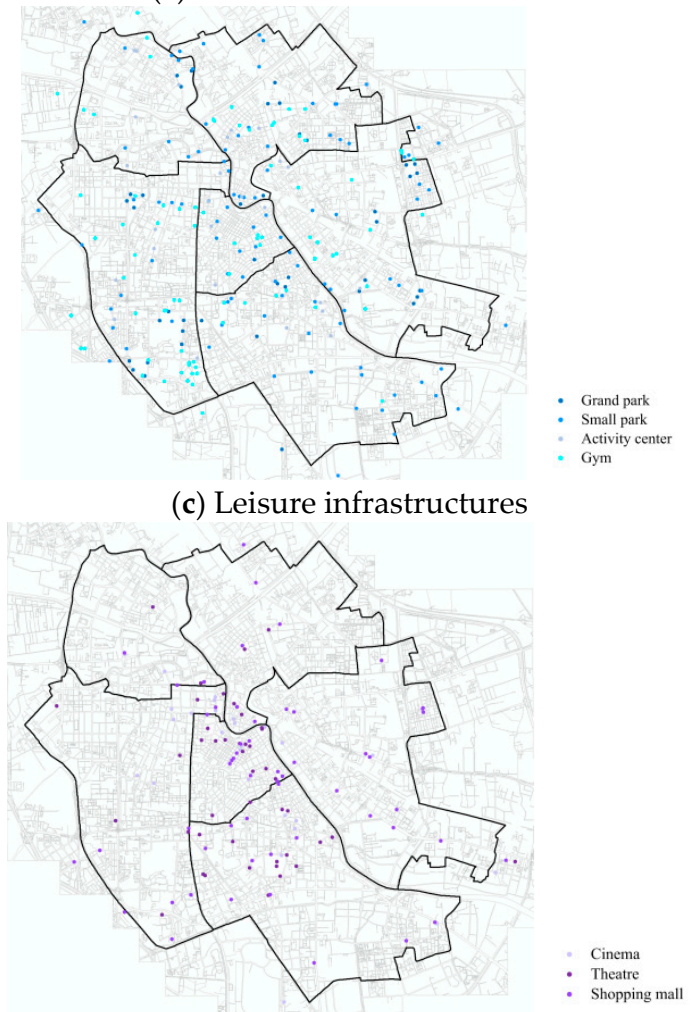

(e) Entertainment infrastructures

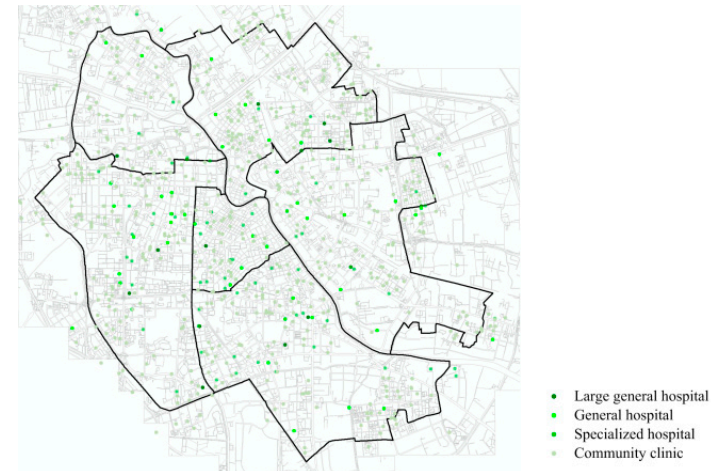

(b) Healthcare infrastructures
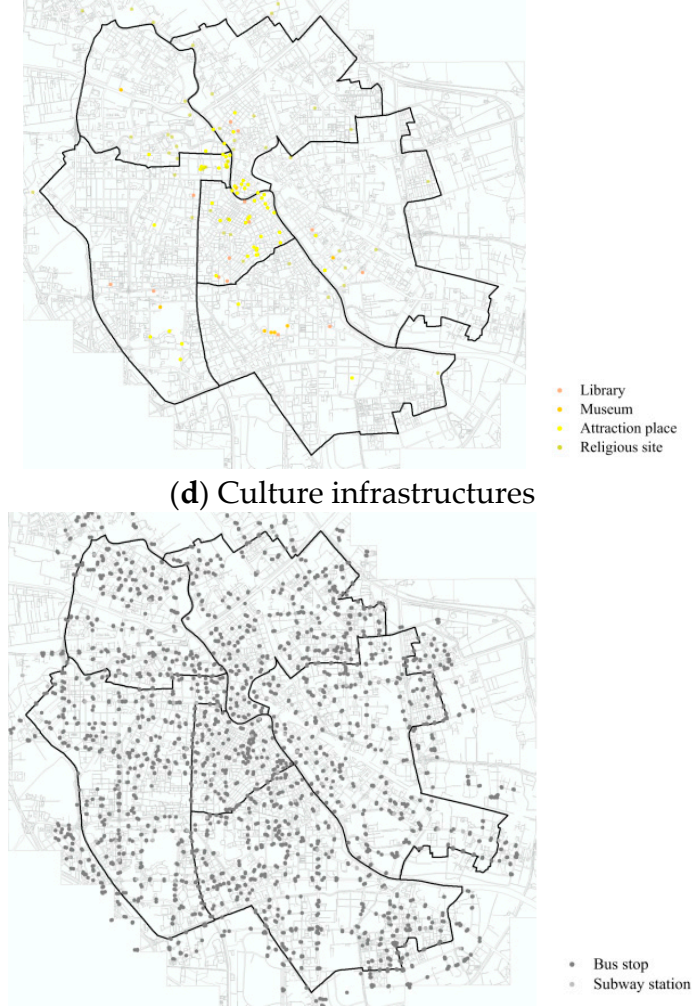

(c) Leisure infrastructures

(d) Culture infrastructures

(f) Commuting infrastructures

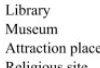

Attraction place

Figure 1. Different categories of social infrastructures in the central districts of Tianjin. 


\subsection{Statistical Analysis and Pattern Recognition}

In our research, the 15-minute walking distance of the community life circle is quantified as $1 \mathrm{~km}$, according to the normal walking speed of adults. The availability factor $a\left(t_{n, i, j}\right)$ of the infrastructure facilities within the neighborhood is considered as a fixed value, due to the same convenience of visiting in the daily life. Meanwhile, without too much emphasis on the subtle differences, the facilities of the same type are regarded as equally important $w_{i, j}$ for the residents. Thus, the cumulative accessibility index $\operatorname{Ind} x\left(O_{n, i}\right)$ of the social infrastructures is able to be simplified as the number of facilities within the spatial scope of $1 \mathrm{~km}$ from each residential community.

The accessibility indexes of the 25 types of social infrastructures were calculated for the 2602 neighborhoods in the central districts of Tianjin. As shown by the statistical results (see Figure 2), the variation of the accessibility (the standard deviation) is relatively big for almost every type of social infrastructure. While the community clinic and bus stop are the two types of infrastructures with the best accessibility, the infrastructures for leisure, culture, and entertainment are always hard to access for residents in daily life.

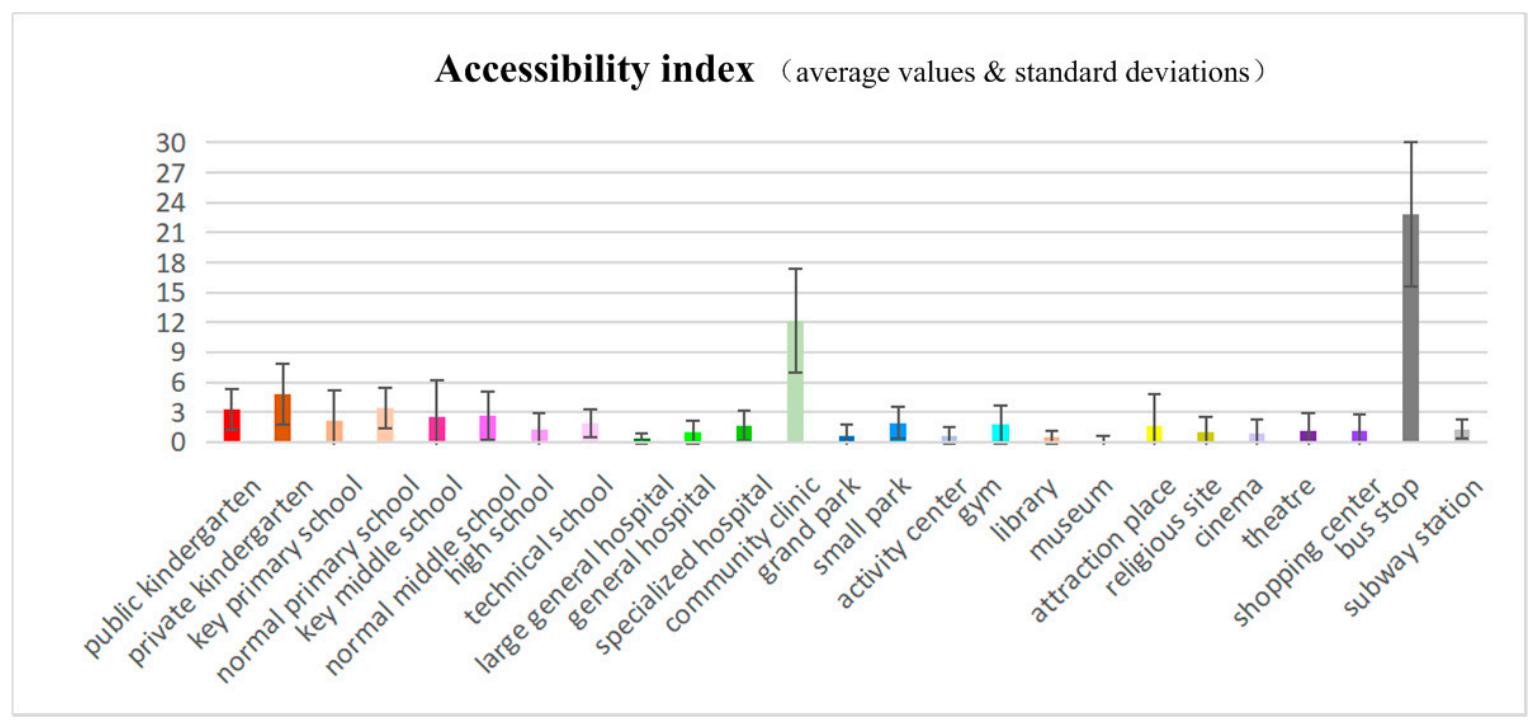

Figure 2. The statistical histogram of the accessibility indexes of 25 types of social infrastructures.

Judging from the quantities (see Figure 3), the educational environment is relatively good in the central districts of Tianjin, with less than 150 neighborhoods not having the access to any type of education facilities. Besides, each neighborhood has at least one bus stop, and two-thirds of them have access to a subway station. Small parks and gyms are provided in more than two-thirds of the neighborhoods for leisure activities. However, the large general hospital, grand parks, activity center, library, museum, attraction place, religious site, cinema, and theatre are the scarce resources within neighborhoods. More than half of the neighborhoods do not have accessibility to at least one of them.

To study the patterns of social infrastructure configurations within the neighborhoods, the correlation analysis was conducted on the different accessibility indexes. According to the results (see Table 1), the average absolute value of the correlation coefficients of the infrastructures is only 0.22 , which means there is a great diversity of configurations among the neighborhoods. The private kindergarten, large general hospital, grand park, and museum are especially independent; the average correlation coefficient of any one of them with other types of infrastructures is just below 0.1. Nevertheless, from all of the figures, two distinct patterns can still be identified. 


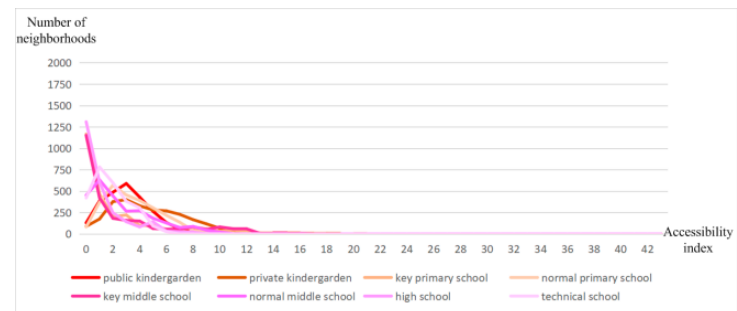

(a) Education infrastructures

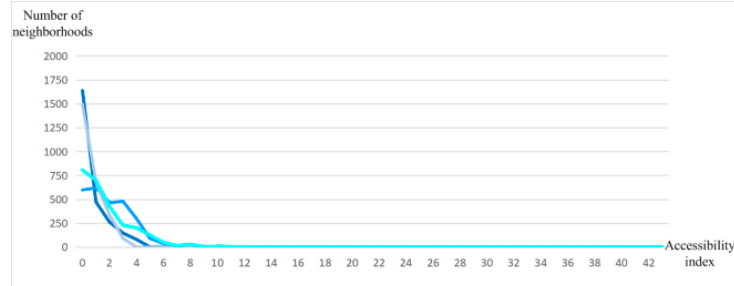

(c) Leisure infrastructures

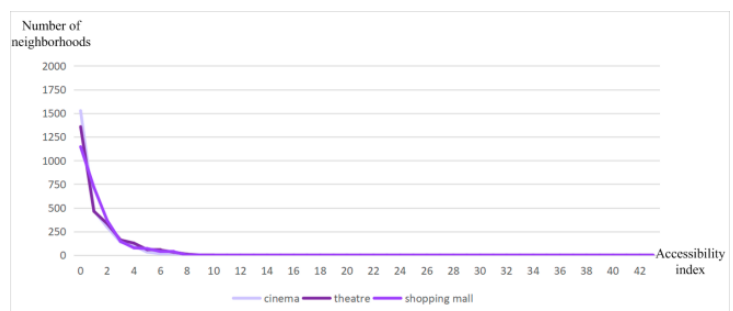

(e) Entertainment infrastructures

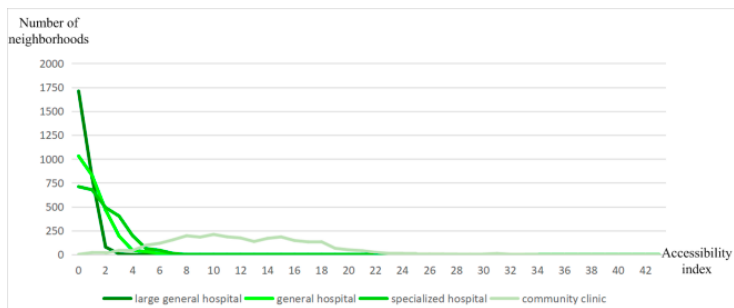

(b) Healthcare infrastructures

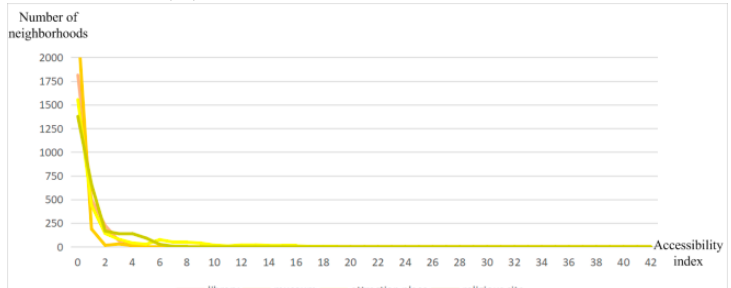

(d) Culture infrastructures

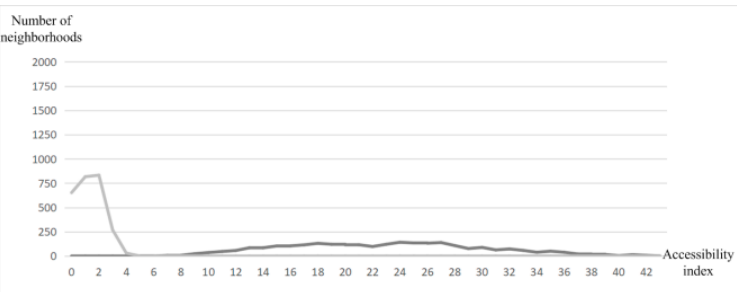

(f) Commuting infrastructures

Figure 3. Frequency diagrams of accessibility measurements of six categories of social infrastructures.

Table 1. The correlation matrix of the accessibility indexes of 25 types of social infrastructures.

\begin{tabular}{|c|c|c|c|c|c|c|c|c|c|c|c|c|c|c|c|c|c|c|c|c|c|c|c|c|c|}
\hline & a & b & c & d & e & f & $\mathrm{g}$ & h & $\mathrm{i}$ & $\mathrm{j}$ & k & 1 & $\mathbf{m}$ & $\mathrm{n}$ & o & p & $q$ & $\mathrm{r}$ & $\mathbf{s}$ & $t$ & u & $\mathbf{v}$ & $\mathbf{w}$ & $x$ & $\mathbf{y}$ \\
\hline $\mathbf{a}$ & 1.00 & -0.01 & 0.42 & 0.40 & 0.46 & 0.53 & 0.21 & 0.26 & -0.09 & 0.15 & 0.27 & 0.28 & 0.12 & 0.27 & -0.13 & 0.13 & 0.21 & -0.06 & 0.28 & 0.13 & 0.10 & 0.15 & 0.26 & -0.01 & 0.35 \\
\hline b & -0.01 & & -0.13 & 0. & -0.11 & 0.1 & -0.15 & -0.07 & 0.09 & 0.16 & -0.16 & 0.27 & 0.08 & & & 0.14 & -0.12 & -0.16 & -0.08 & 0.14 & -0.01 & -0.18 & -0.1 & 0.10 & -0.05 \\
\hline c & 0.42 & 0.13 & 1.00 & & 0.83 & & 0.43 & 0.23 & 0.00 & & 0.60 & 0.29 & -0.01 & & & & 0.49 & & 0.51 & & & 0.48 & 0.47 & & 0.54 \\
\hline $\mathrm{f}$ & & -0.10 & 0.59 & & & & 0.16 & 0.17 & -0.03 & 0.17 & & 0.39 & & & & 0.24 & & -0.08 & 0.52 & 0.40 & & 0.43 & 52 & 0.15 & 0.46 \\
\hline $\mathrm{g}$ & 0.2 & -0.15 & 0.43 & & & & 1.0 & & 0.11 & 0.28 & & & & & 0.02 & 0.09 & 0.22 & -0.05 & & & & & & -0.06 & 0.22 \\
\hline $\mathrm{h}$ & & & & & & & & & & & & & & & & & & & & & & & & & 28 \\
\hline $\mathrm{i}$ & -0.09 & 0.09 & 0.00 & 0.11 & -0.03 & -0.03 & 0.11 & & 1.0 & & & & & & & & 0.04 & & -0.15 & 0.14 & -0.04 & -0.04 & -0.17 & 0.04 & 0.10 \\
\hline $\mathrm{m}$ & & & & & & & & & & & & & & & & & & & & & & & & & 0.00 \\
\hline $\mathrm{n}$ & 0.27 & 0.0 & 0.47 & 0.2 & & 0.3 & 0. & 0.0 & 0.00 & 0.18 & 0.38 & 0.25 & 0.08 & 1. & 0.28 & 0.11 & 0.40 & -0.05 & 0.59 & 0.47 & 0.48 & & 48 & 0.24 & 0.56 \\
\hline o & -0.13 & 0.06 & 0.07 & 0.1 & & 0.0 & -0.02 & 0.8 & & & & 0.2 & D.14 & & & & & 0.02 & 0.24 & & & & 33 & & 0.18 \\
\hline & 0.13 & 0.1 & 0.2 & & & & & & & & & & & & & & & & & & & & & & 20 \\
\hline q & 0.21 & -0.12 & 0.49 & & & & & & & & & & & & & & & & & & & & & & 27 \\
\hline & -0.06 & 0.16 & -0.09 & -0 & -0.07 & -0.08 & -0.05 & 0. & & -0.08 & & -0.17 & -0.01 & 0.05 & & -0.08 & & & & -0.07 & & & & -0.10 & 00 \\
\hline s & 0.28 & -0.08 & 0.51 & 0.04 & & 0.5 & 0.08 & 0.0 & -0.15 & 0.10 & & 0.03 & & 0. & & & 0. & & & 0.49 & & & & 0.24 & 0.59 \\
\hline & & & & & & & & & & & & & & & & & & & & & & & & & 44 \\
\hline $\mathbf{u}$ & & & 0.35 & & & & 0. & 0. & & 0.13 & & & 0.10 & 0.48 & & & & 0.1 & 0.68 & & 1.00 & 0.70 & 0.63 & 0.32 & 54 \\
\hline
\end{tabular}

Note: from a to $y$, in turn, the alphabets in the leftmost column and the topmost row represent the public kindergarten, private kindergarten, key primary school, primary school, key middle school, middle school, high school, technical school, large general hospital, general hospital, specialized hospital, community clinic, grand park, small park, activity center, gym, library, museum, attraction place, religious site, cinema, theatre, shopping mall, bus stop, and subway station.

First, the correlation coefficients (the red colored figures in Table 1) of any two of the shopping mall, cinema, theatre, subway station, and attraction place are above or equal to 0.50 , which is much higher than that of the others. With the average correlation coefficient of the five types of social infrastructures to be 0.63 , it actually reflects the typical entertainment-oriented lifestyle in urban China. The corresponding neighborhoods always lie in the downtown of the city (the commercial center and old city), and the people living around these places do not only have more potential to do culture and entertainment consumption, they also enjoy good commuting services in their daily lives. 
Second, the correlation coefficients (the blue colored figures in Table 1) of any two among the key primary school, key middle school, and normal middle school are all above 0.50 , which are also notable values. The average correlation coefficient of the three types of social infrastructures is 0.67 , which well reflects the typical education-oriented lifestyle, and is common-seen in the "school district" of most Chinese cities. Due to the development laws of the educational industry and the support of local finance, advantageous education resources always tend to concentrate at certain places in a city. People living in the corresponding neighborhoods would enjoy the benefits of the abundant education resources and good environment there.

\subsection{Spatial Analysis and Layout Exploration}

To further explore the layouts of different types of social infrastructures in the city, density maps were generated for spatial analysis with GIS (see Figure 4). In view of the spatial distributions of the facilities, there exists evident disparities in the service provisions. In one aspect, the infrastructure facilities for the satisfaction of basic living demands (e.g., the kindergartens, normal primary school, community clinics, and transportation stations) are relatively evenly distributed in different districts. In another aspect, the high-quality infrastructure facilities (e.g., the key primary school, key middle school, and high school) and the infrastructures operated by private sectors (e.g., the cinemas, theaters, and shopping malls) are always concentrated at certain places in the city. The residents living in the neighborhoods near the hot regions would have more opportunities to visit the corresponding infrastructures and enjoy better living conditions. On the contrary, the residents living in the neighborhoods far away from the hot regions might suffer from poor services in their daily lives.

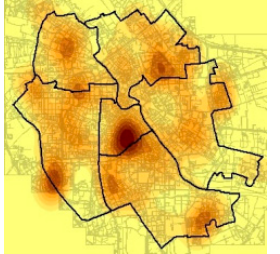

(a) Public

kindergarten

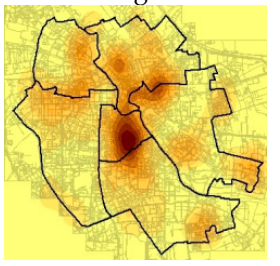

(f) Normal middle

school

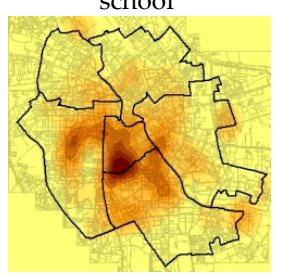

(k) Specialized hospital

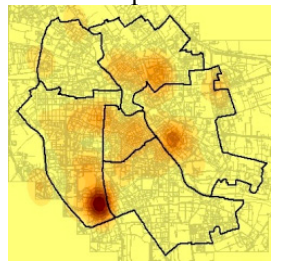

(p) Gym

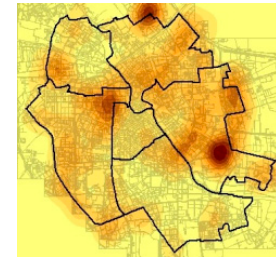

(b) Private

kindergarten

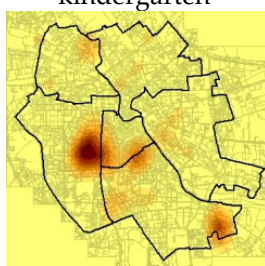

(g) High school

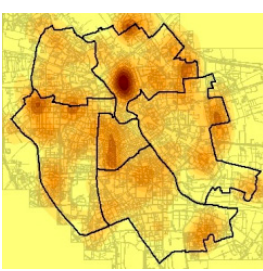

(l) Community clinic

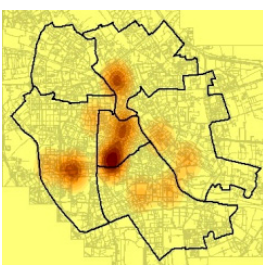

(q) Library

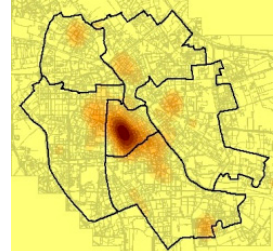

(c) Key primary school

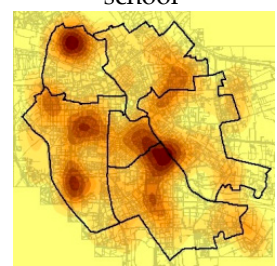

(h) Technical school

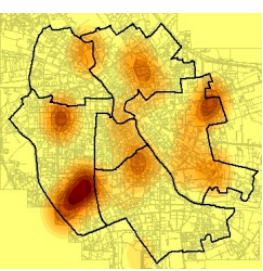

(m) Grand park

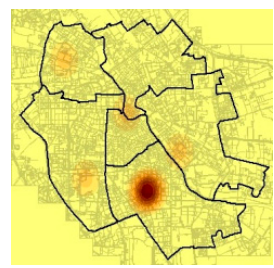

(r) Museum

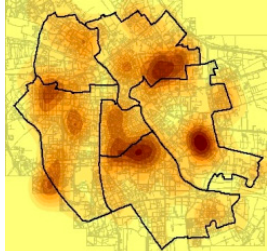

(d) Normal primary school

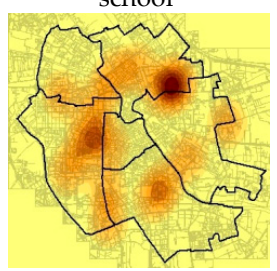

(i) Large general hospital

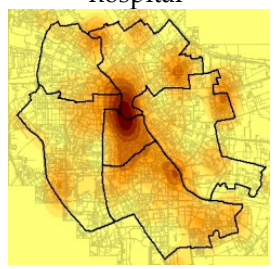

(n) Small park

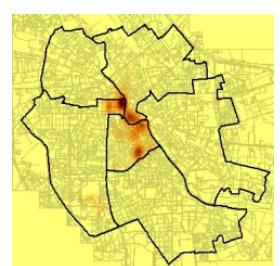

(s) Attraction place

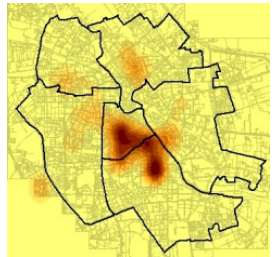

(e) Key middle school

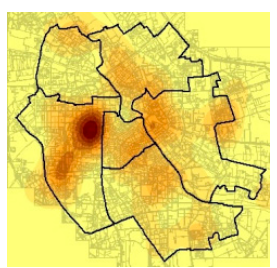

(j) General hospital

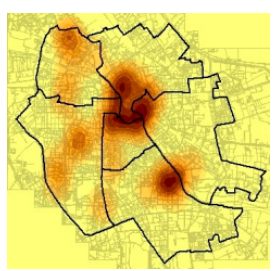

(o) Activity center

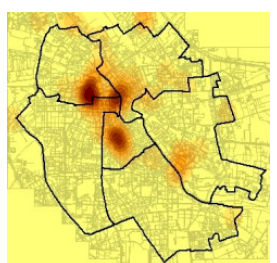

(t) Religious site

Figure 4. Cont . 


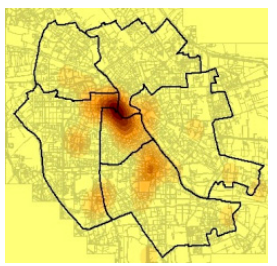

(u) Cinema

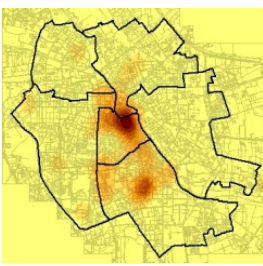

(v) Theatre

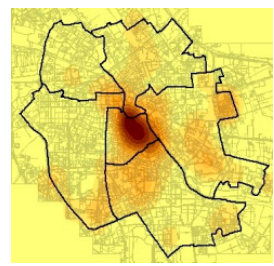

(w) Shopping mall

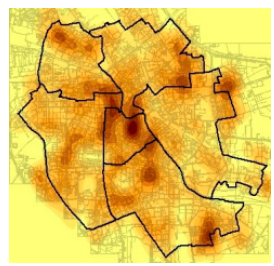

(x) Bus stop

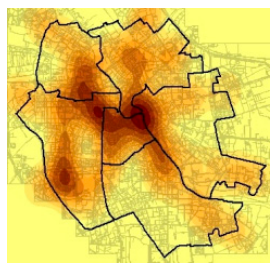

(y) Subway station

Figure 4. Density maps of 25 types of social infrastructures in the central districts of Tianjin.

Combining the density maps of various social infrastructures, the neighborhoods with advantageous living conditions in different aspects show a varied distribution in geography. In regard to education (see Figure 5a) and entertainment (see Figure 5e), the neighborhoods with all of the corresponding accessibility indexes over the average level are mainly located in the central district. While the neighborhoods with high accessibility to the transportation infrastructures cover the largest area of the city (see Figure 5f), the neighborhoods with high accessibility to the culture infrastructures only sparsely exist at the city center (see Figure $5 d$ ). The advantageous neighborhoods in the aspects of healthcare (see Figure $5 b$ ) and leisure (see Figure 5c) are dispersedly distributed in different districts, although their numbers are rather small. In addition, it is worth mentioning that there is no neighborhood that has advantages in all of these aspects, and only 44 neighborhoods $(1.7 \%$ of the total number) have a poor condition in every aspect.

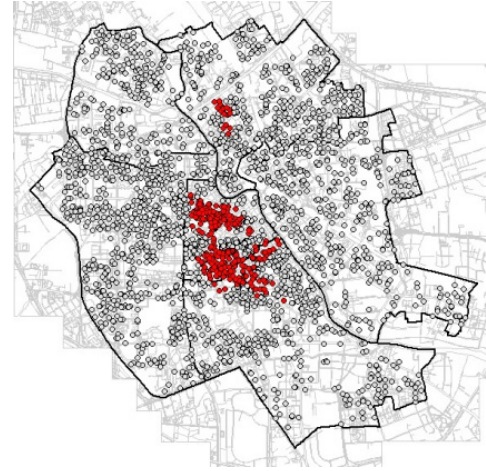

(a) Neighborhoods with advantages in education

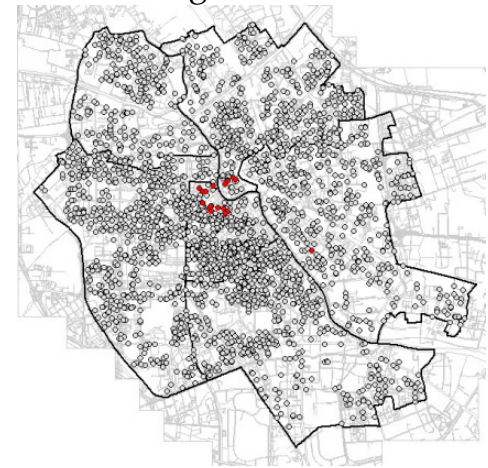

(d) Neighborhoods with advantages in culture

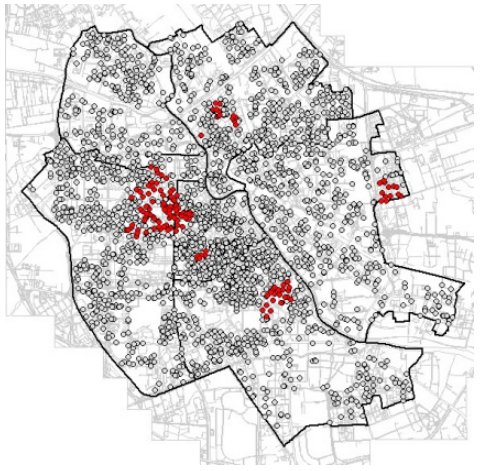

(b) Neighborhoods with advantages in healthcare

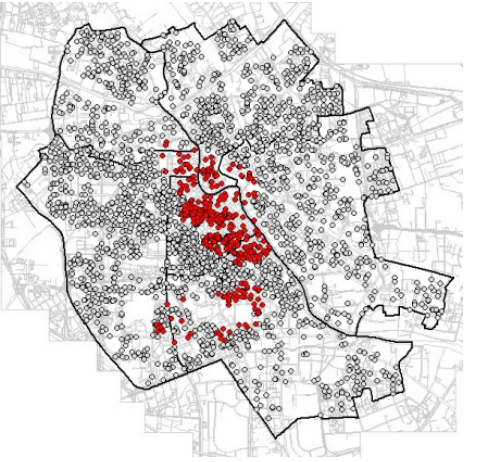

(e) Neighborhoods with advantages in entertainment

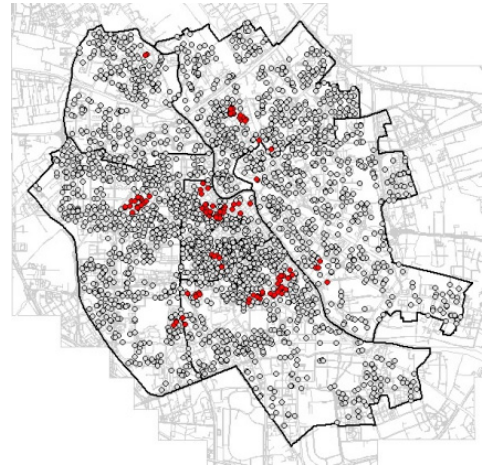

(c) Neighborhoods with advantages in leisure

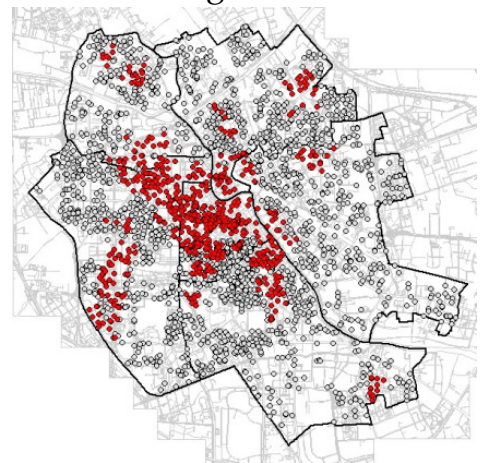

(f) Neighborhoods with advantages in transportation

Figure 5. Spatial distributions of the advantageous neighborhoods in the central districts of Tianjin.

\subsection{Comparative Studies}

For better understanding of the living conditions of diversified neighborhoods, comparative studies were carried out from different perspectives. First, to reflect the social class differences, the living conditions of the neighborhoods of different types of residential communities were studied (see Figure 6b). 
Second, to reveal the regional differences, the living conditions of the neighborhoods belonging to different administrative districts were studied (see Figure $6 \mathrm{c}$ ). Third, to indicate the urbanization level differences, the living conditions of the neighborhoods lying in different urban zones of the city were studied (see Figure 6d).

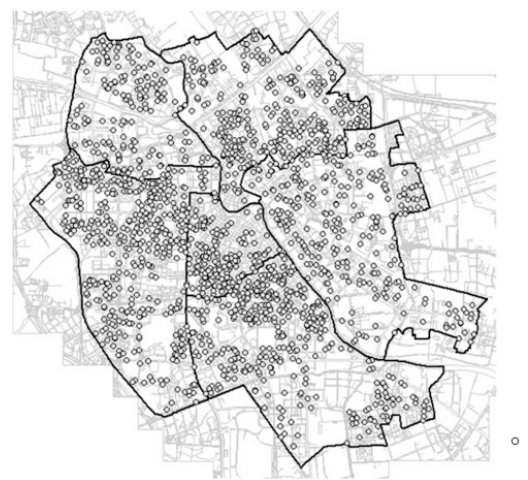

(a) All the neighborhoods

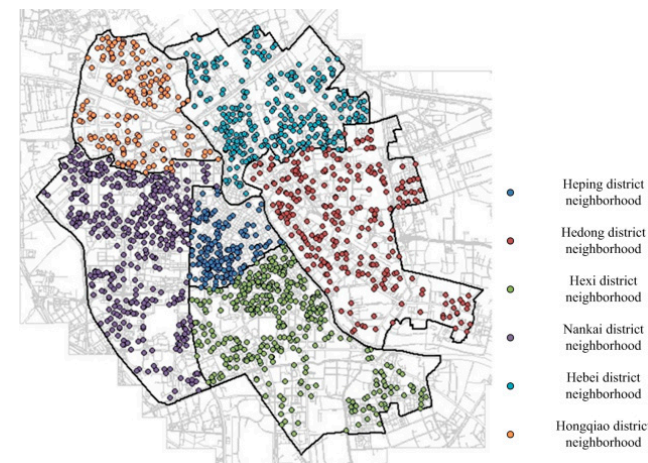

(c) Neighborhoods belonging to different administrative districts

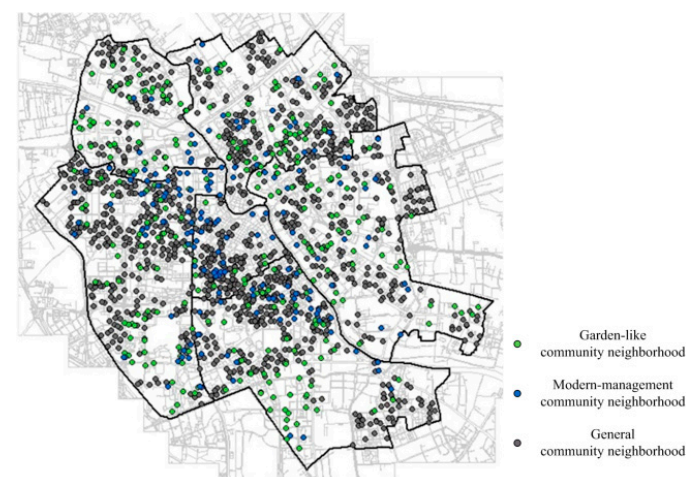

(b) Neighborhoods of different types of residential communities

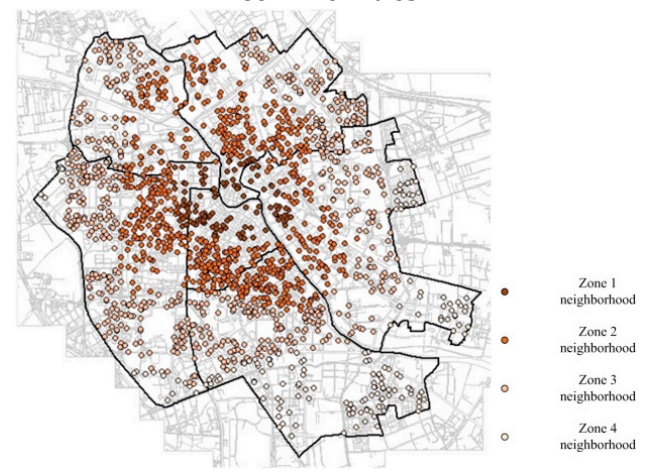

(d) Neighborhoods lying in different urban zones of the city

Figure 6. Spatial distributions of various neighborhoods in the central districts of Tianjin.

\subsubsection{Comparison among Different Types of Residential Communities}

With reference to the standards for the residential building design of Tianjin, the residential communities were classified into three categories, namely the garden-like communities, modern-management communities, and ordinary communities. The garden-like communities are the ones with a high green ratio $(\geq 30 \%)$ and a low plot ratio $(\leq 2)$, which are mostly townhouses or villas occupied by rich people. The modern-management communities are the ones with a high plot ratio $(>2)$ and a high management fee $\left(1 \mathrm{RMB} / \mathrm{m}^{2}\right)$, which are mostly high-end apartments occupied by white-collar workers. The ordinary communities are the rest of communities in which most of the people in the city live.

According to the comparative results of the average accessibility indexes among the neighborhoods of different types of communities (see Figure 7), the neighborhoods of garden-like communities have the worst access to most of the social infrastructures, and on the contrary, those of modern-management communities have little advantages in many aspects, especially for the accessibility to transportation, culture, leisure, and entertainment facilities. It to some extent reflects the different housing preference of different classes of people. The residents living in the neighborhoods of garden-like communities are the people with high socioeconomic status, and they usually have stronger mobility with private vehicles and love to live at quiet places. In contrast, the white collars care more about the services in their surroundings. 


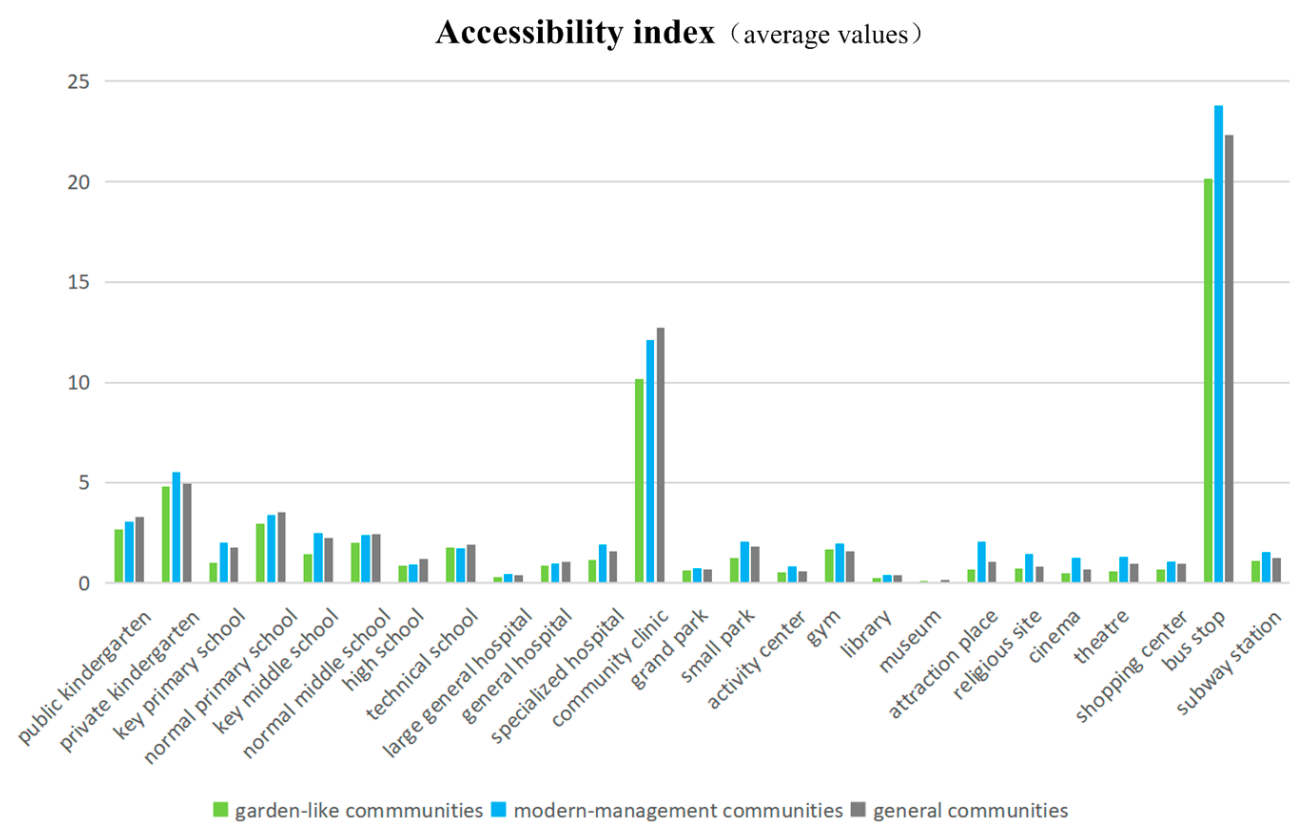

Figure 7. Comparative histograms of the average accessibility indexes of the neighborhoods of different types of residential communities.

\subsubsection{Comparison among Different Administrative Districts}

The central districts of Tianjin are composed of six districts: Heping, Hedong, Hexi, Nankai, Hebei, and Hongqiao. Specialized in different economic and social functions, the six districts have different focuses and levels of capability in public services provision and delivery, which would to some extent influence the living conditions of the neighborhoods.

According to the comparative result of the average accessibility indexes among the neighborhoods belonging to different administrative districts (see Figure 8), Heping is the district characterized by the agglomeration of diverse and high-quality social infrastructure facilities. The residents living in the neighborhoods of Heping district obviously enjoy better services in the daily life than those in other places. On the contrary, the public resources seem not so sufficient within the neighborhoods of Hedong and Hongqiao. Most of the residents in these two districts live a relatively lower standard of life.

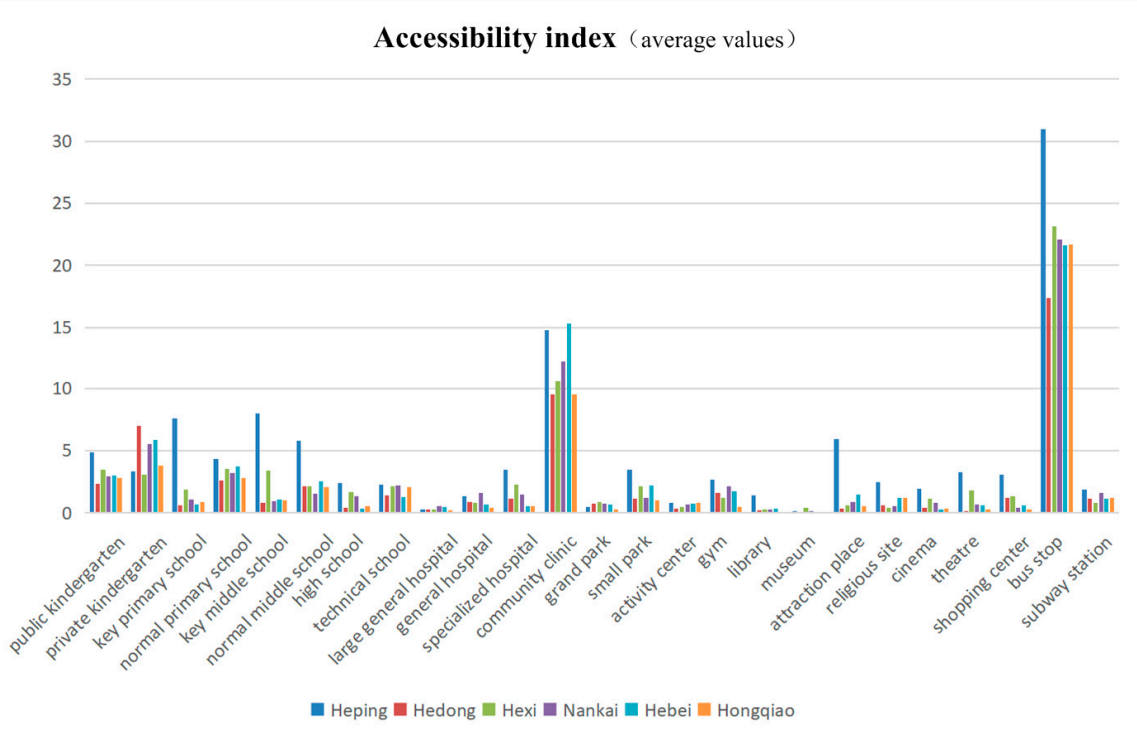

Figure 8. Comparative histograms of the average accessibility indexes of the neighborhoods belonging to different administrative districts. 


\subsubsection{Comparison among Different Urban Zones}

Bordered by the ring roads and beltways from the inside out, the central districts of Tianjin are able to be divided into four circle zones in geography. Due to the different stages of development stages and the market effect controlled by the central place theory, the living conditions of the neighborhoods vary greatly among the four zones of the city.

According to the comparative result of the average accessibility indexes among the neighborhoods in different urban zones (see Figure 9), the capability of service provision as a whole is reduced gradually from circle 1 to circle 4 , with only a few exceptions to the education infrastructures in circle 2. Circle 2 is the most notable zone in the central districts of the city, compared to all of the others. In one aspect, the accessibility of entertainment and transportation infrastructures declines sharply between circle 1 and circle 2 . In another aspect, the education and culture services are rare within the neighborhoods located outside circle 2 .

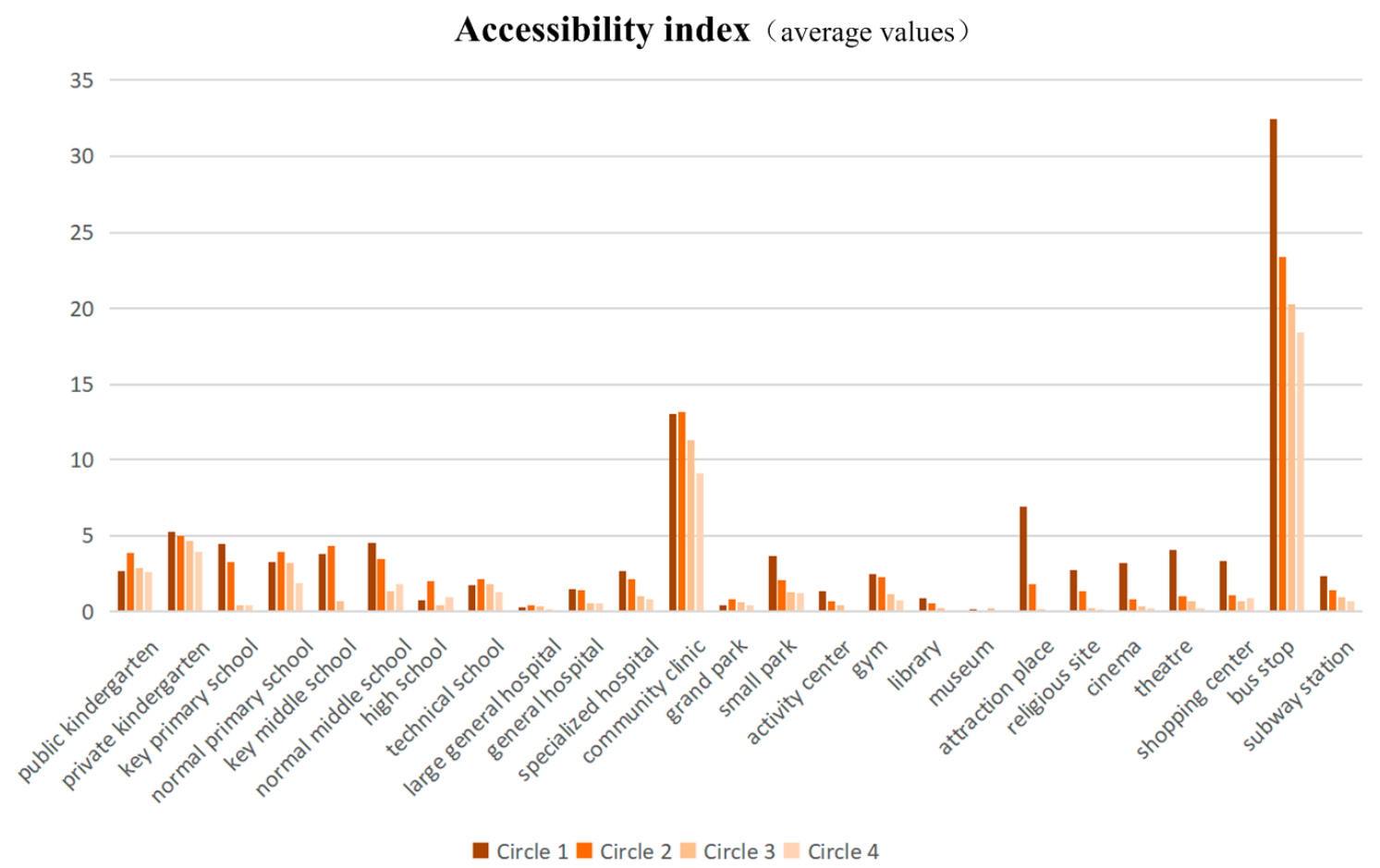

Figure 9. Comparative histogram of the average accessibility indexes of the neighborhoods located in different urban zones.

\section{Conclusions}

The accessibility of various social infrastructures implies opportunities to satisfy the demands of the daily lives of residents. With the aim of understanding the living conditions of Chinese urban neighborhoods, this paper studies the social infrastructure configurations around residential communities based on a cumulative accessibility measurement. From the study case of Tianjin, it is discovered that the living conditions vary greatly among different neighborhoods, but (1) two patterns of social infrastructure configurations are identified, representing the commonly seen entertainment-oriented and education-oriented neighborhoods in the city; (2) the neighborhoods with advantageous living conditions in different aspects are always located in different places, due to the various distributions of social infrastructures; (3) according to the specific criteria of classification, the neighborhoods of different types of residential communities, belonging to different administrative districts, or lying in different urban zones, have distinctive characteristics and living conditions.

All of the findings will help decision makers from both public and private sectors for better policy and strategy making on the sustainable development of social infrastructures. However, for the 
improvement of our research, two issues still need to be considered in the future. First, the mobility of the people is in fact different in their daily lives. Some may be used to traveling by walking in their spare time, but some others may prefer to travel by vehicles. So, it would be better to define the activity space of residents according to these individual characteristics. Second, the living conditions are also related to the subjective cognition of the people. Different people have different preferences or habits in service acquirement. To get a clearer view of the quality of life of the residents in cities, social investigations need to be conducted simultaneously for the correction of the results obtained from the physical world.

Author Contributions: Conceptualization, X.S.; Methodology, X.S.; Writing-Original Draft Preparation, W.W.; Writing-Review \& Editing, X.S.; Project Administration, T.S. and Y.P.W.; Funding Acquisition, T.S.

Funding: This research was jointly supported by UK ESRC (Grant No. ES/N010981/1), the National Natural Science Foundation of China (Grant No. 41501427), the Major projects of the National Social Science Fund (Grant No. 15ZDB173), the Fundamental Research Funds for the Central Universities (Grant No. NKZXB1483), and the Project of Asia Research Center in Nankai University (Grant No. AS1522).

Conflicts of Interest: The authors declare that they have no potential conflicts of interest with respect to the research, authorship, or publication of this article.

\section{References}

1. Karp, D.; Stone, G.; Yoels, W. Being Urban: A Sociology of City Life, 3rd ed.; Praeger: New York, NY, USA, 2015; pp. 119-148. ISBN 978-0-27-595647-9.

2. Marans, R. Quality of urban life \& environmental sustainability studies: Future linkage opportunities. Habitat Int. 2015, 45, 47-52. [CrossRef]

3. Collier, P.; Venables, A. Urbanization in developing economies: The assessment. Oxf. Rev. Econ. Policy 2017, 33, 355-372. [CrossRef]

4. Kanbur, R.; Zhuang, J. Urbanization and inequality in Asia. Asian Dev. Rev. 2013, 30, 131-147. [CrossRef]

5. Sartorius, K.; Sartorius, B. Service delivery inequality in South African municipal areas: A new way to account for inter-jurisdictional differences. Urban Stud. 2016, 53, 3336-3355. [CrossRef]

6. Wang, Y.; Liu, Y.; Li, Y.; Li, T. The spatio-temporal patterns of urban-rural development transformation in China since 1990. Habitat Int. 2016, 53, 178-187. [CrossRef]

7. He, S.; Qian, J. From an emerging market to a multifaceted urban society: Urban China studies. Urban Stud. 2017, 54, 827-846. [CrossRef]

8. Chen, G. Housing the urban poor in post-reform China: Some empirical evidence from the city of Nanjing. Cities 2012, 29, 252-263. [CrossRef]

9. Jiang, S.; Lu, M.; Sato, H. Identity, inequality, and happiness: Evidence from urban China. World Dev. 2012, 40, 1190-1200. [CrossRef]

10. Huang, X.; Yang, Y. Urban redevelopment, gentrification and gentrifiers in post-reform inland China: A case study of Chengdu, China. Chin. Geogr. Sci. 2017, 27, 151-164. [CrossRef]

11. Wang, Y.P.; Wang, Y.; Wu, J. Urbanization and informal development in China: Urban villages in Shenzhen. Int. J. Urban Reg. Res. 2009, 33, 957-973. [CrossRef]

12. Li, Z.; Wu, F. Residential satisfaction in China's informal settlements: A case study of Beijing, Shanghai, and Guangzhou. Urban Geogr. 2013, 34, 923-949. [CrossRef]

13. Wu, L.; Zhi, Y.; Sui, Z.; Liu, Y. Intra-Urban Human Mobility and Activity Transition: Evidence from Social Media Check-In Data. PLoS ONE 2014, 9, e97010. [CrossRef] [PubMed]

14. Ahas, R.; Aasa, A.; Yuan, Y.; Raubal, M.; Smoreda, Z.; Liu, Y.; Tiru, M.; Zook, M. Everyday space-time geographies: Using mobile phone-based sensor data to monitor urban activity in Harbin, Paris, and Tallinn. Int. J. Geogr. Inf. Sci. 2015, 29, 2017-2039. [CrossRef]

15. Zhang, Y.; Martens, K.; Long, Y. Revealing group travel behavior patterns with public transit smart card data. Travel Behav. Soci. 2018, 10, 42-52. [CrossRef]

16. Cheng, Y.; Rosenberg, M.; Wang, W.; Yang, L.; Li, H. Aging, health and place in residential care facilities in Beijing, China. Soc. Sci. Med. 2011, 72, 365-372. [CrossRef] [PubMed] 
17. Wang, D.; Lin, T. Built environment, travel behavior, and residential self-selection: A study based on panel data from Beijing, China. Transportation 2017, 1-24. [CrossRef]

18. Silver, D.; Nichols Clark, T. The power of scenes: Quantities of amenities and qualities of places. Cult. Stud. 2015, 29, 425-449. [CrossRef]

19. Wang, D.; Zhou, M. The built environment and travel behavior in urban China: A literature review. Transp. Res. Part D 2017, 52, 574-585. [CrossRef]

20. Neutens, T.; Schwanen, T.; Witlox, F. The prism of everyday life: Towards a new research agenda for time geography. Transp. Rev. 2011, 31, 25-47. [CrossRef]

21. Wolch, J.; Byrne, J.; Newell, J. Urban green space, public health, and environmental justice: The challenge of making cities 'just green enough'. Landsc. Urban Plan. 2014, 125, 234-244. [CrossRef]

22. Wang, D.; Li, F.; Chai, Y. Activity spaces and sociospatial segregation in Beijing. Urban Geogr. 2012, 33, $256-277$. [CrossRef]

23. Dash, R.; Sahoo, P. Economic growth in India: The role of physical and social infrastructure. J. Econ. Policy Reform 2010, 13, 373-385. [CrossRef]

24. Roskruge, M.; Grimes, A.; McCann, P.; Pott, J. Social capital and regional social infrastructure investment: Evidence from New Zealand. Int. Reg. Sci. Rev. 2012, 35, 3-25. [CrossRef]

25. Sahoo, P.; Dash, R.; Nataraj, G. China's growth story: The role of physical and social infrastructure. J. Econ. Dev. 2012, 37, 53-75. [CrossRef]

26. Wen, H.; Zhang, Y.; Zhang, L. Do educational facilities affect housing price? An empirical study in Hangzhou, China. Habitat Int. 2014, 42, 155-163. [CrossRef]

27. Brasington, D.; Haurin, D.R. Educational outcomes and house values: A test of the value added approach. J. Reg. Sci. 2006, 46, 245-268. [CrossRef]

28. Turner, Y.; Acker, A. Education in the New China: Shaping Ideas at Work; Routledge: New York, NY, USA, 2017; pp. 10-52. ISBN 978-0-75-461914-7.

29. Cheng, L.; Chen, C.; Xiu, C. Excess kindergarten travel in Changchun, Northeast China: A measure of residence-kindergarten spatial mismatch. J. Transp. Geogr. 2017, 60 (Suppl. C), 208-216. [CrossRef]

30. Zheng, S.; Hu, W.; Wang, R. How much is a good school worth in Beijing? Identifying price premium with paired resale and rental data. J. Real Estate Financ. Econ. 2016, 53, 184-199. [CrossRef]

31. Ahmadi-Javid, A.; Seyedi, P.; Syam, S.S. A survey of healthcare facility location. Comput. Oper. Res. 2017, 79, $223-263$. [CrossRef]

32. Pitkin, D.K.; Varda, D.M. Social capital and health care access: A systematic review. Med. Care Res. Rev. 2009, 66, 272-306. [CrossRef] [PubMed]

33. Starfield, B.; Shi, L.; Macinko, J. Contribution of Primary Care to Health Systems and Health. Milbank Q. 2005, 83, 457-502. [CrossRef] [PubMed]

34. Pan, J.; Qin, X.; Li, Q.; Messina, J.P.; Delamater, P.L. Does hospital competition improve health care delivery in China? China Econ. Rev. 2015, 33 (Suppl. C), 179-199. [CrossRef]

35. McCollum, R.; Chen, L.; ChenXiang, T.; Liu, X.; Starfield, B.; Jinhuan, Z.; Tolhurst, R. Experiences with primary healthcare in Fuzhou, urban China, in the context of health sector reform: A mixed methods study. Int. J. Health Plan. Manag. 2014, 29, 107-126. [CrossRef] [PubMed]

36. Ramesh, M.; Wu, X.; He, A.J. Health governance and healthcare reforms in China. Health Policy Plan. 2014, 29, 663-672. [CrossRef] [PubMed]

37. Peters, K.; Elands, B.; Buijs, A. Social interactions in urban parks: Stimulating social cohesion? Urban For. Urban Green. 2010, 9, 93-100. [CrossRef]

38. McCormack, G.R.; Rock, M.; Toohey, A.M.; Hignell, D. Characteristics of urban parks associated with park use and physical activity: A review of qualitative research. Health Place 2010, 16, 712-726. [CrossRef] [PubMed]

39. Xiang, W.; Huang, S.S.; Stodolska, M.; Yu, Y. Leisure time, leisure activities, and happiness in China: Evidence from a national survey. J. Leis. Res. 2015, 47, 556-576. [CrossRef]

40. Chin, M.K.; Edginton, C.R.; Su, X.; Zhou, T. Sports for All (SFA) Strategies: An Integrated 21st Century Model of Leisure, Sports and Health in Guangzhou, China. World Leis. J. 2007, 49, 155-165. [CrossRef]

41. Guo, X.; Dai, J.; Xun, P.; Jamieson, L.M.; He, K. Sport facility proximity and physical activity: Results from the Study of Community Sports in China. Eur. J. Sport Sci. 2015, 15, 663-669. [CrossRef] [PubMed] 
42. Liu, H.; Li, F.; Xu, L.; Han, B. The impact of socio-demographic, environmental, and individual factors on urban park visitation in Beijing, China. J. Clean. Prod. 2017, 163, S181-S188. [CrossRef]

43. Mathews, V. Aestheticizing Space: Art, Gentrification and the City. Geogr. Compass 2010, 4, 660-675. [CrossRef]

44. Wu, M.; Wall, G. Visiting heritage museums with children: Chinese parents' motivations. J. Herit. Tour. 2017, 12, 36-51. [CrossRef]

45. Stern, M.J.; Seifert, S.C. Cultural clusters: The implications of cultural assets agglomeration for neighborhood revitalization. J. Plan. Educ. Res. 2010, 29, 262-279. [CrossRef]

46. Wei, Z.; Zhen, F.; Shan, L.; Mou, S.; Ming, L. Study on the Spatio-temporal Distribution Patterns of Cultural Facilities in Shenzhen. Urban Stud. 2007, 14, 8-13. [CrossRef]

47. Friedmann, J. Reflections on Place and Place-making in the Cities of China. Int. J. Urban Reg. Res. 2007, 31, 257-279. [CrossRef]

48. Brown, P.H.; Tierney, B. Religion and subjective well-being among the elderly in China. J. Socio-Econ. 2009, 38, 310-319. [CrossRef]

49. Liang, Z.; Bao, J. Tourism gentrification in Shenzhen, China: Causes and socio-spatial consequences. Tour. Geogr. 2015, 17, 461-481. [CrossRef]

50. Lyubomirsky, S.; Sheldon, K.M.; Schkade, D. Pursuing happiness: The architecture of sustainable change. Rev. Gen. Psychol. 2005, 9, 111-131. [CrossRef]

51. Kilroy, A. Intra-urban spatial inequalities: Cities as 'urban regions'. In World Development Report; World Bank: Washington, DC, USA, 2009.

52. Xue, D.; Hang, J.; Ma, B.; Kang, Y. Spatial distribution characteristics and hot zone patterns of entertainment industry in Xi'an. Acta Geogr. Sin. 2014, 69, 541-552. [CrossRef]

53. Zhu, H.; Liu, J.; Chen, C.; Li, J.; Tao, H. A spatial-temporal analysis of urban recreational business districts: A case study in Beijing, China. J. Geogr. Sci. 2015, 25, 1521-1536. [CrossRef]

54. Lu, Y. The malling of the movies: Film exhibition reforms, multiplexes, and film consumption in the new millennium in urban China. J. Chin. Cinemas 2016, 10, 205-227. [CrossRef]

55. Jewell, N. Shopping Malls and Public Space in Modern China, 1st ed.; Routledge: London, UK, 2016; pp. 153-178. ISBN 978-1-31-705515-0.

56. Cheng, E.; Li, H.; Yu, L. A GIS approach to shopping mall location selection. Build. Environ. 2007, 42, 884-892. [CrossRef]

57. Wang, D.; Chai, Y.; Li, F. Built environment diversities and activity-travel behaviour variations in Beijing, China. J. Transp. Geogr. 2011, 19, 1173-1186. [CrossRef]

58. Jensen, O.B. Flows of meaning, cultures of movements-urban mobility as meaningful everyday life practice. Mobilities 2009, 4, 139-158. [CrossRef]

59. Ziari, H.; Keymanesh, M.R.; Khabiri, M.M. Locating stations of public transportation vehicles for improving transit accessibility. Transport 2007, 22, 99-104. [CrossRef]

60. Bergstad, C.J.; Gamble, A.; Gärling, T.; Hagman, O.; Polk, M.; Ettema, D.; Friman, M.; Olsson, L.E. Subjective well-being related to satisfaction with daily travel. Transportation 2011, 38, 1-15. [CrossRef]

61. Næss, P. Residential location, transport rationales and daily-life travel behaviour: The case of Hangzhou Metropolitan Area, China. Prog. Plan. 2013, 79 (Suppl. C), 1-50. [CrossRef]

62. Ji, J.; Gao, X. Analysis of people's satisfaction with public transportation in Beijing. Habitat Int. 2010, 34, 464-470. [CrossRef]

63. Zheng, S.; Hu, X.; Wang, J.; Wang, R. Subways near the subway: Rail transit and neighborhood catering businesses in Beijing. Transp. Policy 2016, 51, 81-92. [CrossRef]

64. Guo, J.; Sun, M.; Wang, T.; Lu, L. Transportation development and congestion mitigation measures of Beijing, China. Mitig. Adapt. Strateg. Glob. Chang. 2015, 20, 651-663. [CrossRef]

65. Chai, Y.; Zhang, X.; Sun, D. A study on life circle planning based on space time behavioural analysis: A case study of Beijing. Urban Plan. Forum 2015, 61-69. [CrossRef]

66. Li, M. The Planning Strategies of a 15-minute Community Life Circle Based on Behaviors of Residents. Urban Plan. Forum 2017, 111-118. [CrossRef]

67. Fleischer, F. "To Choose a House Means to Choose a Lifestyle." The Consumption of Housing and Class-Structuration in Urban China. City Soc. 2007, 19, 287-311. [CrossRef] 
68. Gao, M.; Ahern, J.; Koshland, C.P. Perceived built environment and health-related quality of life in four types of neighborhoods in Xi'an, China. Health Place 2016, 39 (Suppl. C), 110-115. [CrossRef] [PubMed]

69. Lotfi, S.; Koohsari, M.J. Measuring objective accessibility to neighborhood facilities in the city (A case study: Zone 6 in Tehran, Iran). Cities 2009, 26, 133-140. [CrossRef]

70. Delmelle, E.C.; Casas, I. Evaluating the spatial equity of bus rapid transit-based accessibility patterns in a developing country: The case of Cali, Colombia. Transp. Policy 2012, 20, 36-46. [CrossRef]

71. Handy, S.L.; Niemeier, D.A. Measuring accessibility: An exploration of issues and alternatives. Environ. Plan. A 1997, 29, 1175-1194. [CrossRef]

72. Geurs, K.T.; Van Wee, B. Accessibility evaluation of land-use and transport strategies: Review and research directions. J. Transp. Geogr. 2004, 12, 127-140. [CrossRef]

73. Luo, W.; Qi, Y. An enhanced two-step floating catchment area (E2SFCA) method for measuring spatial accessibility to primary care physicians. Health Place 2009, 15, 1100-1107. [CrossRef] [PubMed]

74. Navinfo. Available online: http:/ /www.navinfo.com/index.aspx (accessed on 8 September 2017).

75. Fang.com. Available online: http://tj.fang.com/ (accessed on 5 September 2017).

(C) 2018 by the authors. Licensee MDPI, Basel, Switzerland. This article is an open access article distributed under the terms and conditions of the Creative Commons Attribution (CC BY) license (http://creativecommons.org/licenses/by/4.0/). 